\title{
is Research Square \\ Integrating Artificial Intelligence to create a building that can adapt to future challenges
}

Aref Maksoud ( $\square$ amaksoud@sharjah.ac.ae)

University of Sharjah

Hayder Basel Al-Beer

University of Sharjah

Research Article

Keywords:

Posted Date: March 7th, 2022

DOI: https://doi.org/10.21203/rs.3.rs-1383695/v1

License: (9) (i) This work is licensed under a Creative Commons Attribution 4.0 International License. Read Full License 


\section{Abstract}

Adaptability is a crucial quality in nature, and Artificial Intelligence (Al) provides leverage for adaptability in Architecture. This paper integrates Al to create self-learning buildings that can adapt to future challenges. The aim is to make buildings that collect data from their environment through sensors and adjust according to these data. The approach followed in this paper starts making an extensive research on the use of Al in Architecture. The data gathered from that research was then used to design this building. The design of this building follows a parametric approach with the help of machine learning in the form of computational design tools. An algorithm was designed with Grasshopper Scripting to generate documents that biomimetics the Coral Growth process and adapt that form to the selected site of the project. To ensure that the generated form is adaptable, multiple analyses were made, such as sunlight, radiation, and shadow analysis, before selecting the form and finishing the form development. The result was an environmentally responsive form that extends from the site's surroundings, which have high levels of adaptability. Integrating technology in the architecture of future buildings provides adaptable buildings and helps save some of the energy used by buildings and thus build a sustainable planet.

\section{Introduction}

Integrating Artificial Intelligence within architecture is done through the machine mimics actions related to the human mind. The ability to mimic actions such as learning and problem-solving refers to the desired attribute from artificial intelligence: its ability to think and take steps that have the best chance of achieving a specific goal [1]. The advancement of technology is increasing the evolvement of Al to benefit a wide variety of industries [2]. One of the examples that focused on this topic is the movie Transcendence. This movie's story predicted that a computer would be able to create a technological singularity, where technological progress would rapidly accelerate beyond the capability of human beings. After an accident with the research team leader, his team studies the feasibility of

uploading his consciousness into the quantum computer away from his dying body. In reality, this kind of system would be connected using a complex approach based on algorithms, architecture, psychology, and quantum computing [3]. In this study, we explore the potential of integrating Artificial Intelligence within architecture to create self-learning buildings that can adapt to future challenges and enhance the performance of buildings.

\subsection{Background.}

By looking at the factors that influenced architecture throughout history, it can be noticed that a new historical event happens every few decades, such as a natural disaster, war, or pandemic, which inspires architects, engineers and designers to address new design challenges [4]. This study aims to create a building that uses a system that provides innovative solutions for any potential challenge facing the building. Such a system would take advantage of the latest machine learning technologies. It would merge between sensors and bio-digital materials, which works perfectly together to deal with any challenge [5]. An example of this would be the challenges created during the COVID-19 era. In this case, the building would adapt by activating social distancing from within the building, which could be done through the communication between the Al cloud system of the building and the robots which are inside the building. This means the Al would take the necessary actions to adapt and achieve social distancing [6]. Another way to deal with COVID-19 challenges could be by placing innovative skin on the buildings' interior walls, which do not pick up germs. This can ensure that the spaces are sanitized at all times [7].

The goal in this study in this study is to make a Self-learning Building. It would be a building that can adapt and learn from all sorts of aspects in its environment [8]. For example, if this project is done in a particular place, the 
intelligent system of the building would be able to study and collect information internally about the culture of that place and adapt itself to that culture. It would use sensors to know the number of people in the building, the period of time that they spend together, the clothes they are wearing, and the actions they are taking. After a period of time, it would see patterns and learn from them to predict what will happen in the future [9]. Another example of what the building can learn is its site's environmental conditions, which are sensed externally. This means the building would be able to collect and store data about the ecological conditions and the energy use of the building. Based on the data it collects, it decides the necessary action needed to reduce the energy use of the building, such as changing the tint of the windows to reduce the amount of heat in the building [10].

\subsection{The use of Al to enhance building performance.}

When it comes to the performance of buildings, new automation systems can be used to control security, comfort, and energy efficiency [11]. Al enables buildings to become places driven by real-time data and feedback, communicating with itself like a living organism [12]. It creates a system where the building, smartphones, cars, and public places share to improve living conditions, limit waste, increase safety, and limit traffic. This would allow the building Al to predict any challenges that might come up [13].

Al also opens the doors to create smart homes, living spaces that are complex living real-time data-driven organisms [14]. As architects, the challenge is how to use Al to fit into the design language of the home better to improve the lives of the residents [15]. With Al, we would be able to tailor the building performance according to the people's needs and have it learn, adapt and respond from the data that it receives from the user [16]. Al in buildings takes complete care of residents' comfort and safety and helps in energy and financial savings [17]. Al-based energy management platforms can track usage patterns to create tenants' proper conditions, which conserves both energy and money [18]. Figure 1 shows The Nest Thermostat, an excellent example of a system that can adapt and keep the building at a safe and optimal temperature; it can alert users if the temperature increases to reach a dangerous range. Al devices can analyze data from sensors to monitor leaks or malfunctions. This makes it easier than ever to track the building's performance and efficiency [19]. In addition to that, building managers can maximize operational efficiency, utilize assets reliably, and improve the comfort level of occupants [21].

\subsection{The use of $\mathrm{Al}$ in the design process.}

As architects, we start our projects by spending many hours on research to understand the design philosophy of that project and similar past projects. However, this process takes much time, where Al comes in [22]. Al can collect and combine limitless amounts of data with little time, make decisions, and give recommendations that ease the architect's research process [23]. The architect would be able to test many ideas and conceptual designs simultaneously without needing the slow process of pen and paper, resulting in understanding a better design philosophy in a faster strategy. It is a world where Al has become a design strategy used to leverage the design process. However, it is not convenient to automate the entire design process and solely depend on Al as there are always possible errors. The real advantage of using Al comes from collaborating between human intelligence and Artificial Intelligence [24].

Parametric Computational Design is a significant field where Al and Architecture work together harmoniously, where Al tools have become influential in architecture. Parametric Design allows us to create a parameter-based system that generates forms and structures with such complexity that these forms would not have been possible to be imagined or sketched by pen and paper without these tools [25]. Al Software like Grasshopper Scripting gives the architect the ability to use geometric component-based programming with complex algorithms to generate 
design variations that follow a specific design vocabulary and offer many options [26]. It is almost like an architect's own programming language. These tools can be made even more vital when paired with the Virtual Reality (VR) and Augmented Reality (AR) devices where you would be able to use devices just like the Magic Leap to observe your design as if it is built in front of you and make adjustments from a different perspective [27].

\section{Research Method}

The approach followed in this paper is divided into three phases. The first phase is The Form Generation Process. In this phase, a concept for an adaptable organism is selected to inspire the form generation strategy. After that, an algorithm is designed using Grasshopper scripting to generate various adaptive forms. The second phase is the Form Selection Process. In this phase, the forms generated in the previous phase get filtered according to many different analyses such as structure, radiation, and shadow analysis. The filtration process will help in selecting the most environmentally responsive form. In phase 3 , the final selected generation is developed further to finalize the design and be more ecologically responsive.

\subsection{Phase 1: Form Generation process. 2.1.1. Concept Development.}

The main theme of this project was adaptation, so its concept is biomimicking, a process in nature for adaptation. The process that was bio mimicked is the growth of the Bone Cellular Structures, which is shown in Figure 2. The goal was to biomimicry the process of growth of these organisms that causes them to evolve into an adaptive form. These organisms grow in a way that produces voids in structures of different sizes. In architecture, such voids could help create different-sized patios that allow sunlight to go through the building to reach the internal spaces and allow the wind to flow through the building and naturally ventilate the building, which makes an environmentally responsible form. These structures also melt into each other forming bridges between the different cells. The formed bridges would act as a connection that can connect the functions on different levels [29].

\subsubsection{Grasshopper Script Design.}

To generate architectural forms that biomimicry the growth of the Bone Cellular Structures, intelligent computational design technology, and component-based programming such as Grasshopper were used in the design process. This design technology allowed in designing an algorithm that creates a system that can generate complex formsbased on logic. The computational design tools and principles were used to leverage in designing a Grasshopper definition that can generate adaptive forms that biomimetics that natural process. The Cocoon plugin was used in designing this definition because it helps in generating organic forms that connect the masses by melting them into each other. As shown in Figure 3, the main component in the right box is called Cocoon, which is the core of the script. The Cocoon generates the form based on the inputs connected to it, which are showninbox on the left side,and they are called Charges. These charges resemble three input parameters. The first parameter is the site surrounding blocks which are shown in Figure 4-using the site surroundings as a parameter guarantees generating a form that is specifically tailored for the selected site. The second parameter is the connections lines that include the connection to the surrounding blocks, the entrances to the site, and the overall circulation pattern in the site. Using this as a parameter helps in defining the mobility and circulation path of the building. To generate a final form, the volume of the function was used as the third input. The volume was used as an input parameter 
instead of the area of each function to generate 3D forms, not 2D patterns. In the end, the last component on the right is the Smooth component which is used to smoothen the connection between the masses.

\subsection{Phase 2: Form selection process.}

\subsubsection{Experimental studies.}

The approach followed to generate an adaptive, environmentally responsive form goes through the process of Experimental Studies. In this phase, tens of experimental studies get generated then filtered by analyzing and selecting the most adaptive form. To achieve this, the Grasshopper definition was developed further by using the Millipede plugin. This plugin gives the ability to analyze the structure of each generated form and gives important values such as the max deflection, weight, yield, bending moment, and more. The process of generation for all the experimental studies was done using the grasshopper Galapagos tool. The Galapagos is an Artificial Intelligence tool in Grasshopper that changes the selected parameters to find the best solution which maximizes or minimizes a selected value. In this case, the value that was selected to be minimized is the maximum deflection of each form which was calculated with the millipede components. The parameters that were getting altered to change the form were the radius and the position of each cocoon charge assigned to the site surrounding blocks and connections. Figure 5 shows the best 24 generated experimental studies with the Galapagos.

\subsubsection{Selection Analysis.}

Experimental studies that were generated in the previous stage go through the analysis in this stage. Figure 6 shows all the structural analyses for the generated forms. The colors show the distribution of the deflection around the form; the red color shows the high deflection areas, and the blue color shows lower amounts of deflection distribution. The filtration process will depend on the forms with the lowest max deflection, deflection distribution pattern, the density of the structure, and the availability of errors in the form. According to these criteria, the best four forms are generations $21,22,24$, and 24 . These four forms will go through shadow and radiation analysis to select the most adaptive final form. Figure 7 shows the shadow analysis for the four selected forms. It can be seen from figure 7 that the best selection would be generation 21. Since this selection has bigger curvature, it provides a bigger surface area towards the side of the sun movement and casts shadows for a longer time of the day with only 1 hour of direct sunlight hitting the internal part of the building. Figure 7 also shows the radiation analysis for the same four experimental studies. Similarly, the same selection performed the best in terms of the radiation on the internal part of the building with a value below $467.98 \mathrm{kWh} / \mathrm{m}^{2}$, which makes sense since that form will have the least amount of direct sun exposure. The performed analysis helped in selecting the most environmentally responsive form.

\subsection{Phase 3: Form development process.}

\subsubsection{Skin and structure development.}

After selecting the most adaptive form, the next stage will be developing this form into a finalized form. In this stage, another Grasshopper definition was designed to generate the skin and the structure of the building. As you can see in Fig. 8, this definition uses the Weaverbirds plugin, which helps in generating the triangle-shaped panels that flow the geometry of the form, which is shown in Fig. 8. It also helps in generating the structural members that are supporting these panels. The skin that is used for the building is smart skin. It can sense the sun's heat using Al and change the tint of the glass when the heat increases and decreases. The panels that are facing the sun moving 
from the south will be filled with solar PV panels to generate energy for the building. As for the rest of the panels that are facing the other sides, they will be filled with smart glass, which helps bring defuse light into the building.

\section{Results And Discussion}

\subsection{Adaptive expansion system using Al.}

The final form of the building was produced after finishing the form development, and its shown in Figure 9. As seen from the figure, the strategy of using $\mathrm{Al}$ in the design process helped in creating an elegant original looking building that is adapted to the site. However, the story doesn't end here because a new analysis must be made to test the performance of the final building after the development and to check if the building is environmentally responsive. To analyze the performance, a new Grasshopper algorithm was made using the Ladybug plugin, which is shown in figure 10. The table in figure 10 shows the results of the analysis that was generated from the algorithm. As seen from the table, the total radiation per year is $161.36 \mathrm{kWh} / \mathrm{m}^{2}$. To know if that is a good result, it will be compared to EmiratesGBC BEA Project from the EmiratesGBC 2020 Green Building Market Brief, which is shown in figure 11. The table in figure 11 shows that the best performers in terms of radiation are the buildings that have less than $171 \mathrm{kWh} / \mathrm{m}^{2}$ for hotels, $193 \mathrm{kWh} / \mathrm{m}^{2}$ for resorts, $92 \mathrm{kWh} / \mathrm{m}^{2}$ for schools and $378 \mathrm{kWh} / \mathrm{m}^{2}$ for malls [30]. Figure 4 shows that the major part of this building is an Al Mall, and there are some parts in the building which functions as an Al Hotel and Al Institute. When comparing our results to the BEA, it can be concluded that the building is considered a Best Performer when it comes to the mall and hotel and a median performer when it comes to the institute. These results prove that the building generated by the Al is, in fact, Environmentally Responsive. In addition, it can be noticed from figure 10 that the PV panels which are placed on the south façade provide $368070.02 \mathrm{kWh}$ per year which is $12 \%$ of the building's energy.

\subsection{Adaptive expansion system using Al.}

Al has many potentials in design. In this stage, an Al engine called Deepart.io was used to predict the future expansion of the building on the project's site and the city of Dubai. This is a global Al engine that has been used by international universities like MIT \& organizations like AA in London. This engine can alter a picture based on a given style which acts as the parameter which controls the output. So, a picture of the site was inserted as input with another picture of one of the experimental studies, as shown in figure 12. The Al was able to study the style of the building and produce an output showing how the entire site would look like when filled with this form. In Architectural terms, this Al engine was able to predict future expansion based on its information as a parameter. This makes architecture no longer about one building; it's about an adaptive system that can be applied in any location. Just by changing the picture of the site to a picture of a different site, the Al will adapt the form to the new site and produce a different result.

\section{Conclusion}

Adaptive designs are the key to creating sustainable architecture, and with Al, we can mimic adaptivity in architecture from nature. The journey of achieving adaptability in this project was made on different phases:

- Phase 1: Using computational design tools such as Grasshopper scripting to design a script that can generate different kinds of adaptable forms. 
- Phase 2: The generation of experimental studies and selecting the best form based on structure, shadow, and radiation analysis.

- Phase 3: The development of the skin and the structure of the building, which consisted of triangular panels filled with PV panels from the south and smart glass from the other sides.

After these phases, more analyses were done to test the final performance of the building. The radiation analysis resulted in $161.36 \mathrm{kWh} / \mathrm{m}^{2}$, which was compared to the values of EmiratesGBC BEA Project from the EmiratesGBC 2020 Green Building Market Brief to prove that the resultant form is, in fact, environmentally responsive. Another analysis was done to test the performance of the PV panel in producing energy for the building, which showed that the PV panel covers $12 \%$ of the buildings' energy. An Al engine was then used in making an adaptation system for the building.

In conclusion, this research explored the potential of using Al in architecture, and with the results that showed how the technology helped in creating an environmentally responsive design, it is very clear that Al technologies are powerful strategies to be considered and implemented within architecture. The implementation of Al technologies within architecture starts from the beginning of the design process all the way to the functionality of the actual building. Dubai, being one of the competitive countries when it comes to technology, has big potential in implementing a project like this. The big limitation in this field is the scarcity of minds that can develop good Al technology, which makes implementation expensive. Finally, design and technology are increasingly becoming more connected to each other; it will open a door for new areas of research and redefine how future architecture will look like.

\section{Declarations}

\section{ACKNOWLEDGEMENTS (10 PT)}

This research was supported/partially supported by the University of Sharjah, College of engineering, Architectural engineering department. We thank our colleagues from the Architectural engineering department who provided insight and expertise that greatly assisted the research.

This paper and the research behind it would not have been possible without the exceptional support of Eng. Haydar Basel Kamil Al-Beer, we thank him for his great contribution and assistance with a particular technique and methodology.

We would also like to show our gratitude to the "anonymous" reviewers for their so-called insights. We are also immensely grateful to IJRES Committee. for their comments on an earlier version of the manuscript, although any errors are our own and should not tarnish the reputations of these esteemed persons.

\section{References}

1. J. Choi, M. Won and S. Lee, "63906 Vision based self learning mobile robot using machine learning algorithms(Robotics and Mechatronics)", The Proceedings of the Asian Conference on Multibody Dynamics, vol. 20105, no. 0, pp._63906-1_-_63906-9_, 2010. Available: 10.1299/jsmeacmd.2010.5._63906-1_.

2. K. Dimitropoulos, P. Daras, S. Manitsaris, F. Fol Leymarie and S. Calinon, "Editorial: Artificial Intelligence and Human Movement in Industries and Creation", Frontiers in Robotics and Al, vol. 8, 2021. Available: 
10.3389/frobt.2021.712521.

3. K. Andrew (Producer), P. Wally (Director), (2014) Transcendence USA: Warner Bros

4. A. Hendy, A., 2020. The New Design Considerations in the Residential Buildings' Interiors at the Post-Corona (COVID-19) Era. Journal of Advanced Research in Dynamical and Control Systems, 12(SP8), pp.444-458.

5. A. Estévez and D. Navarro, "Biomanufacturing the Future: Biodigital Architecture \& Genetics", Procedia Manufacturing, vol. 12, pp. 7-16, 2017. Available: 10.1016/j.promfg.2017.08.002.

6. S. Ahmed, "Covid, Al, and Robotics-A Neurologist's Perspective", Frontiers in Robotics and Al, vol. 8, 2021. Available: 10.3389/frobt.2021.617426.

7. T. Assaf, "A Frequency Modulation-Based Taxel Array: A Bio-Inspired Architecture for Large-Scale Artificial Skin", Sensors, vol. 21, no. 15, p. 5112, 2021. Available: 10.3390/s21155112.

8. N. Cortiços, "Self-learning and Self-repairing Technologies to Establish Autonomous Building Maintenance", MATEC Web of Conferences, vol. 278, p. 04004, 2019. Available: 10.1051/matecconf/201927804004.

9. M. Hutson, "How artificial intelligence could negotiate better deals for humans", Science, 2017. Available: 10.1126/science.aap9309.

10. S. Mehra and R. Sharma, "Performance Analysis of Artificial Intelligence Based MPPT Techniques for a Solar System Under Changing Environmental Conditions", SSRN Electronic Journal, 2020. Available: $10.2139 /$ ssrn.3573604.

11. G. Birangal, D. Admane and S. Shinde, "Energy Efficiency Approach to Intelligent Building", International Journal of Engineering Research, vol. 4, no. 7, pp. 389-393, 2015. Available: 10.17950/ijer/v4s7/711.

12. N. Cotrufo, E. Saloux, J. Hardy, J. Candanedo and R. Platon, "A practical artificial intelligence-based approach for predictive control in commercial and institutional buildings", Energy and Buildings, vol. 206, p. 109563, 2020. Available: 10.1016/j.enbuild.2019.109563.

13. D. Alexander, and McFadden, 2020. 5 Ways Artificial Intelligence Is Changing The World Of Architecture. [online] Interestingengineering.com. Available at: <https://interestingengineering.com/5-ways-artificialintelligence-is-changingarchitecture\#: :text=Al\%20will\%20make\%20the\%20planning,shorten\%20design\%20and\%20building\%20time.> [Accessed 24 November 2020].

14. Z. PALA and O. ÖZKAN, "Artificial Intelligence Helps Protect Smart Homes against Thieves", DÜMF Mühendislik Dergisi, 2020. Available: 10.24012/dumf.700311.

15. S. Chua, "Behaviour recognition in smart homes", Journal of Ambient Intelligence and Smart Environments, vol. 5, no. 1, pp. 133-133, 2013. Available: 10.3233/ais-120193.

16. Y. Zhao, T. Li, X. Zhang and C. Zhang, "Artificial intelligence-based fault detection and diagnosis methods for building energy systems: Advantages, challenges and the future", Renewable and Sustainable Energy Reviews, vol. 109, pp. 85-101, 2019. Available: 10.1016/j.rser.2019.04.021.

17. N. Joshi, 2019. How Al Is Making Buildings Smart And Intelligent. [online] Forbes. Available at: <https://www.forbes.com/sites/cognitiveworld/2019/08/13/how-ai-is-making-buildings-smart-andintelligent/?sh=cee725a28d7d>.

18. C. Chen, Y. Hu, M. Karuppiah and P. Kumar, "Artificial intelligence on economic evaluation of energy efficiency and renewable energy technologies", Sustainable Energy Technologies and Assessments, vol. 47, p. 101358, 2021. Available: 10.1016/j.seta.2021.101358. 
19. K. Oberste-Ufer, 2019. 7 Ways Artificial Intelligence Is Revolutionizing Architecture. [online] EN - dormakaba Blog. Available at: <https://blog.dormakaba.com/7-ways-artificial-intelligence-is-revolutionizing-architecture/> [Accessed 21 November 2020].

20. M. Wollerton, 2018. Nest's Thermostat Gets Smarter, Adds A Temperature Sensor. [online] CNET. Available at: $<$ https://www.cnet.com/reviews/nest-learning-thermostat-third-generation-review/> [Accessed 30 November 2020].

21. H. Rocha, I. Honorato, R. Fiorotti, W. Celeste, L. Silvestre and J. Silva, "An Artificial Intelligence based scheduling algorithm for demand-side energy management in Smart Homes", Applied Energy, vol. 282, p. 116145, 2021. Available: 10.1016/j.apenergy.2020.116145.

22. T. Al-Azzawi and Z. Al-Majidi, "Parametric architecture: the second international style", IOP Conference Series: Materials Science and Engineering, vol. 1067, no. 1, p. 012019, 2021. Available: 10.1088/1757899x/1067/1/012019.

23. T. Kurtoglu, M. Campbell and J. Linsey, "An experimental study on the effects of a computational design tool on concept generation", Design Studies, vol. 30, no. 6, pp. 676-703, 2009. Available: 10.1016/j.destud.2009.06.005.

24. H. Wang, "Real-Time Data-Based Fault Diagnosis System", Advanced Materials Research, vol. 189-193, pp. 2621-2624, 2011. Available: 10.4028/www.scientific.net/amr.189-193.2621.

25. R. Oxman, "Thinking difference: Theories and models of parametric design thinking", Design Studies, vol. 52, pp. 4-39, 2017. Available: 10.1016/j.destud.2017.06.001.

26. C. Cubukcuoglu, B. Ekici, M. Tasgetiren and S. Sariyildiz, "OPTIMUS: Self-Adaptive Differential Evolution with Ensemble of Mutation Strategies for Grasshopper Algorithmic Modeling", Algorithms, vol. 12, no. 7, p. 141, 2019. Available: 10.3390/a12070141.

27. M. PHILIPS, 2020. The Present And Future Of Al In Design (With Infographic). [online] Toptal Design Blog. Available at: <https://www.toptal.com/designers/product-design/infographic-ai-indesign\#: :text=Designers\%20working\%20with\%20Al\%20can,adjustments\%20based\%20on\%20that\%20data.>.

28. R. Naboni and K. Anja, "Design and Additive Manufacturing of Lattice-based Cellular Solids at Building Scale", 2017, pp. 369-375, doi: 10.5151/sigradi2017-058..

29. D. Chen, B. Ross and L. Klotz, "Lessons from a Coral Reef: Biomimicry for Structural Engineers", Journal of Structural Engineering, vol. 141, no. 4, p. 02514002, 2015. Available: 10.1061/(asce)st.1943-541x.0001216.

30. "EMIRATESGBC 2020 GREEN BUILDING MARKET BRIEF", Emiratesgbc.org, 2020. [Online]. Available: https://emiratesgbc.org/wp-content/uploads/2020/09/UAE-Brief_NewTemplate_electronic_final.pdf.

\section{Figures}




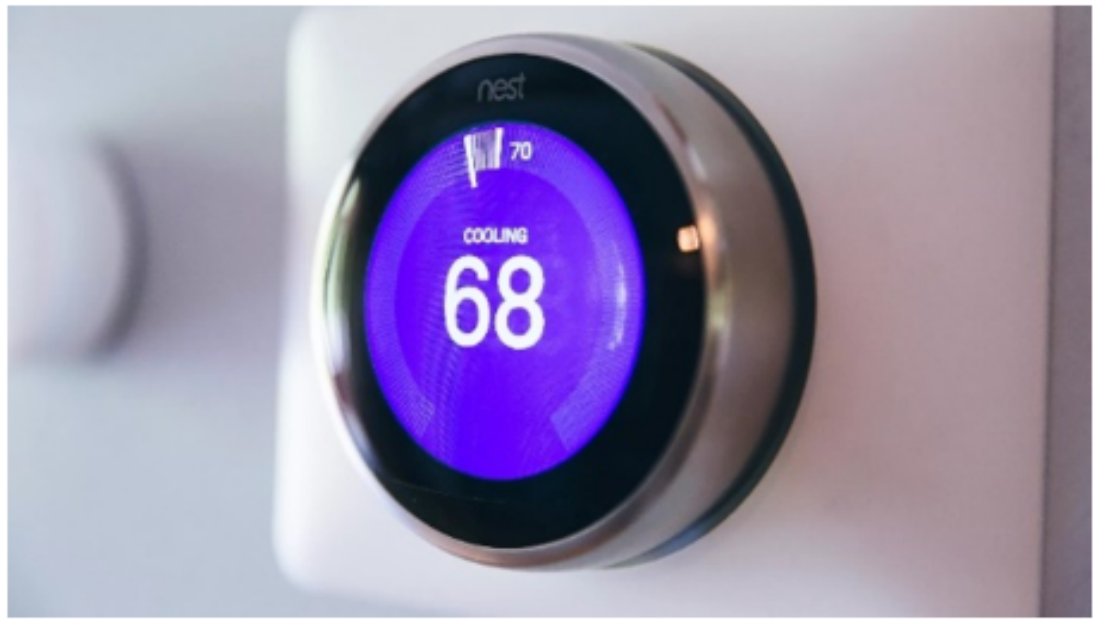

\section{Figure 1}

The Nest thermostat Al device which keeps the building at optimal temperature [20].

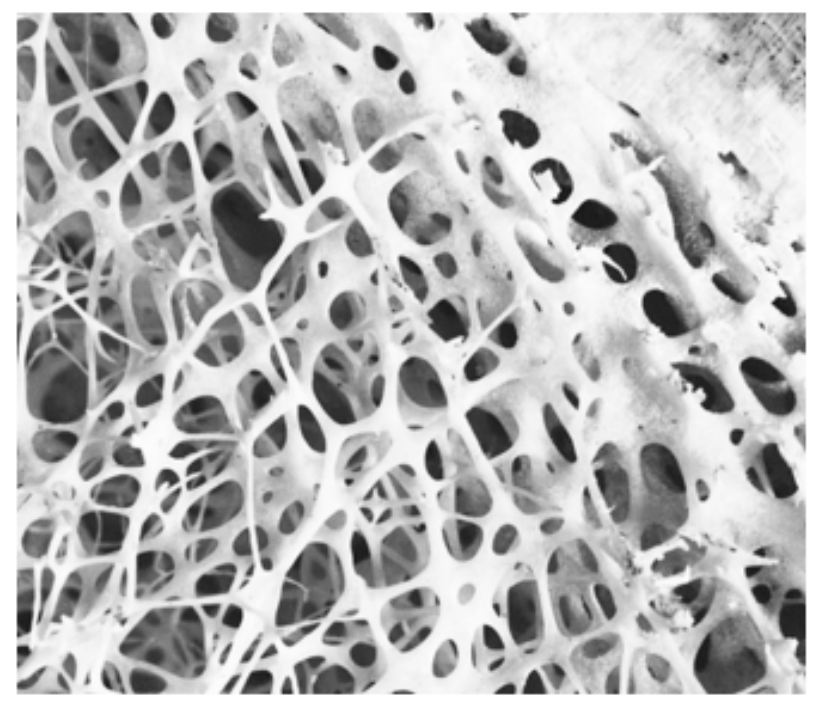

\section{Figure 2}

Cellular structures growth pattern [28].

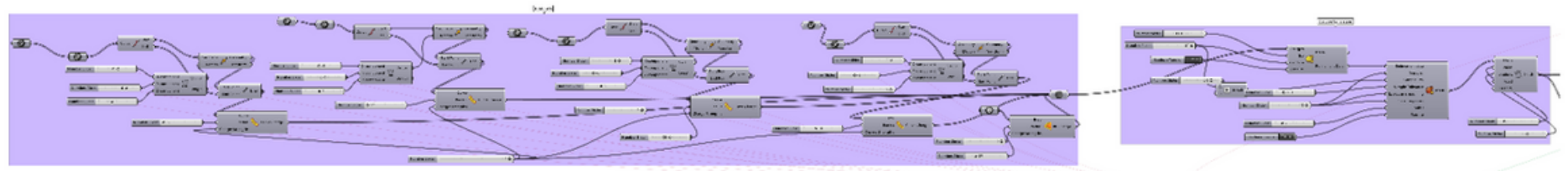

\section{Figure 3}

The Grasshopper Algorithm that was designed to generate the forms for this building. 


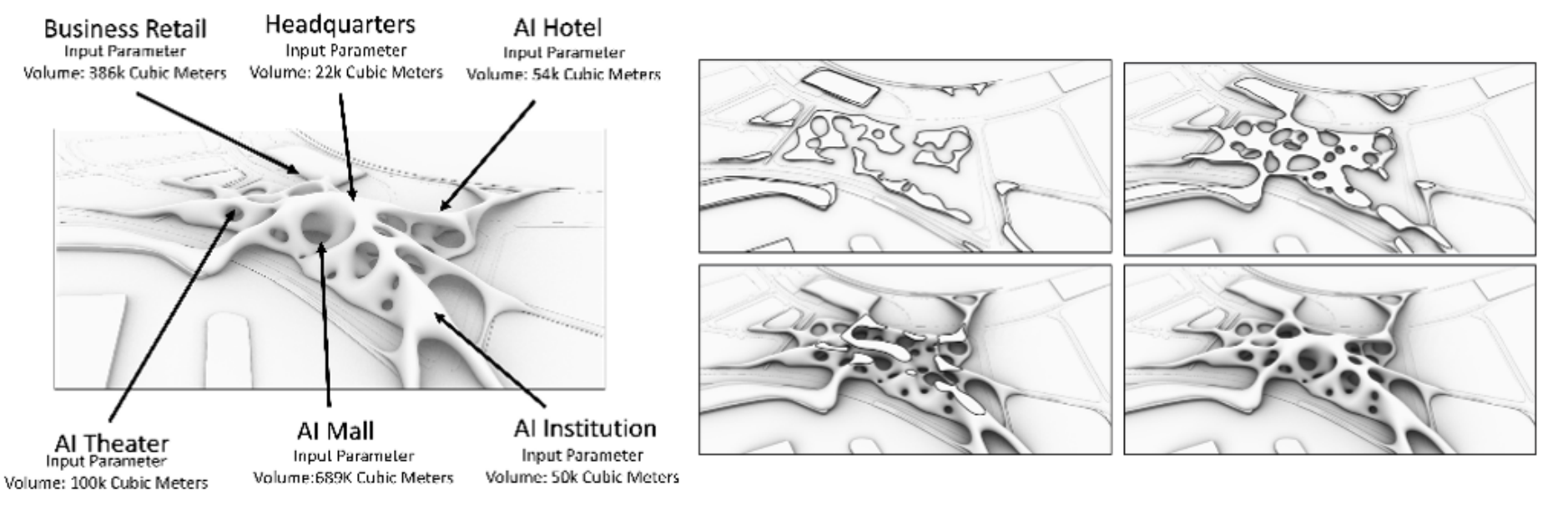

\section{Figure 4}

The site surroundings and the volume of each function were the parameters defined how the building will look like.

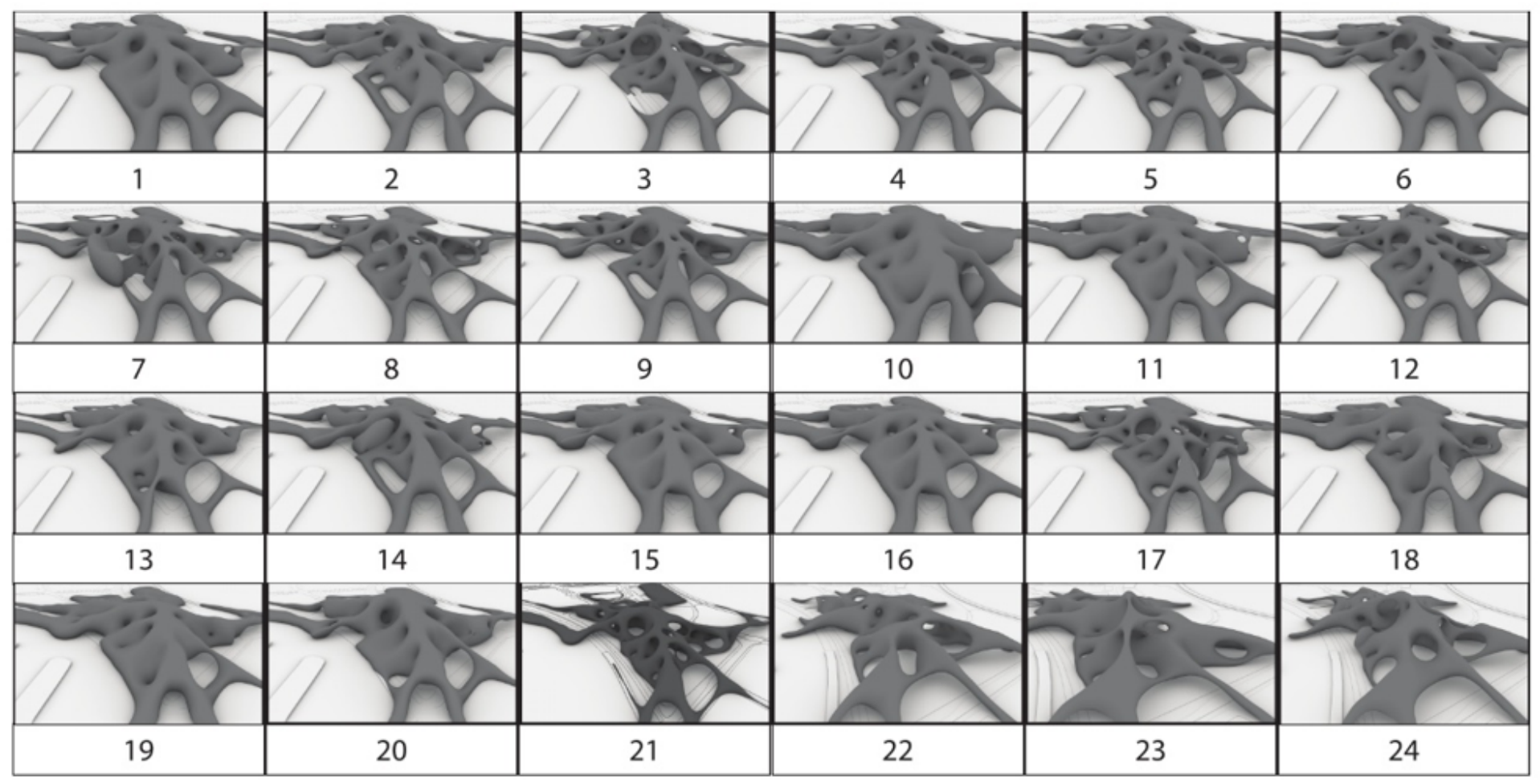

Figure 5

The Experimental Studies that were made in the process of generating the best form. 


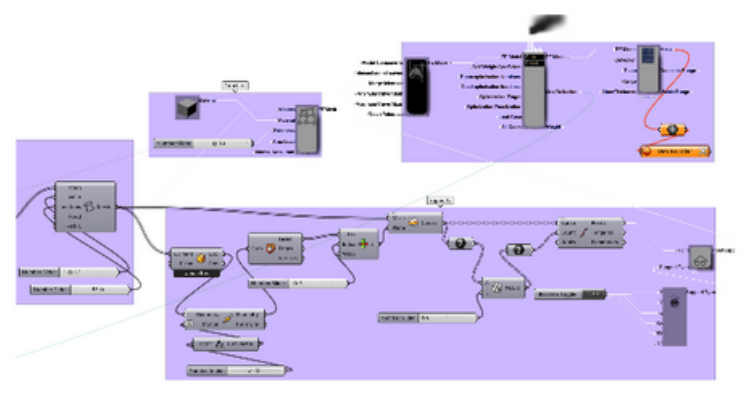

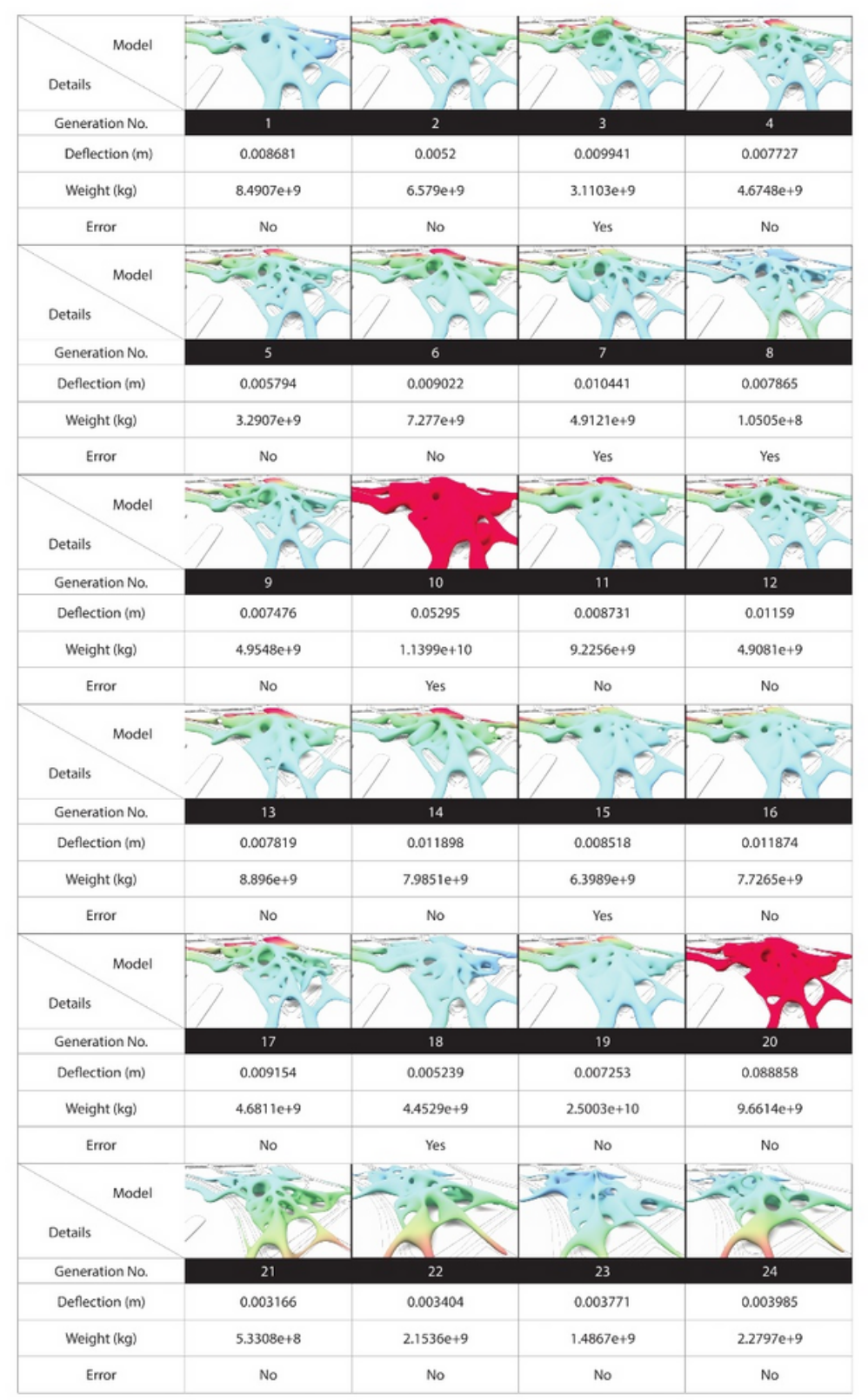

\section{Figure 6}

The algorithm and results of the structure analysis. 

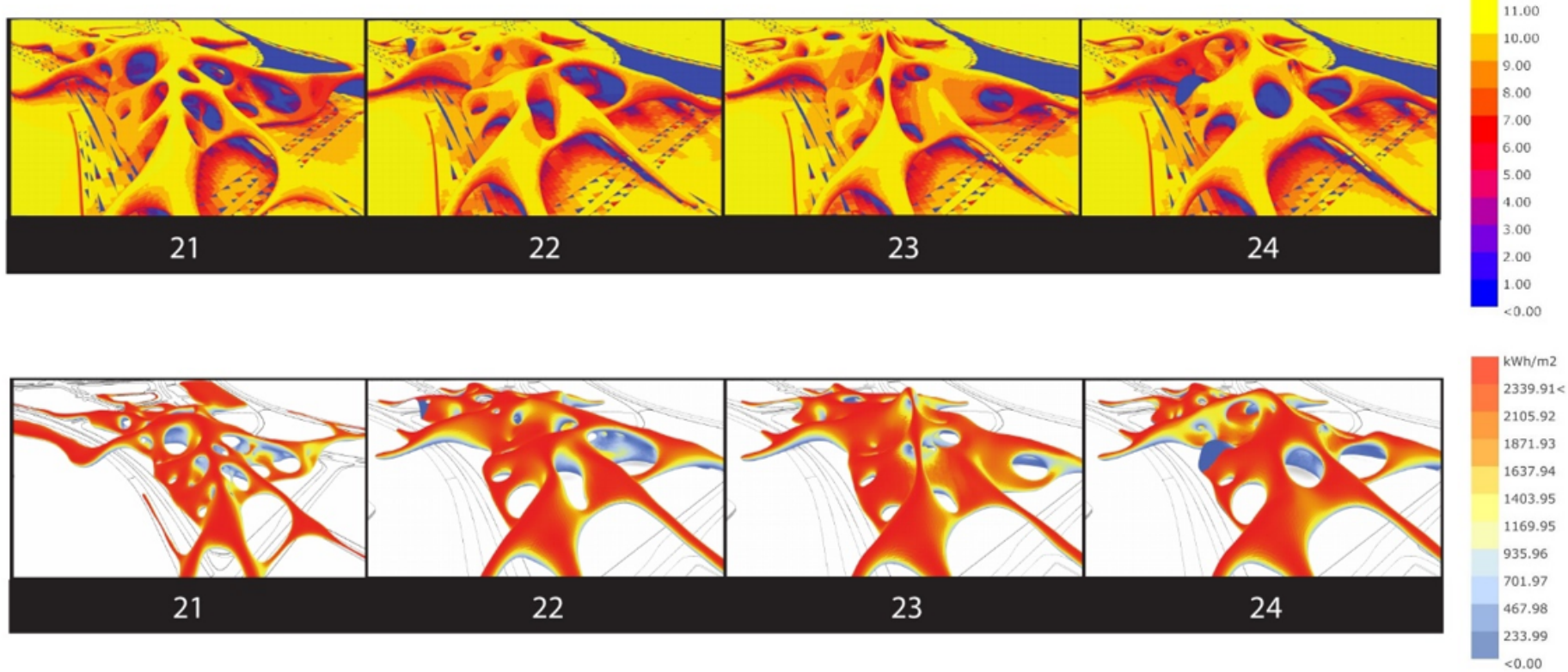

Figure 7

Shadow and radiation analysisfor the best 4 generatioons.
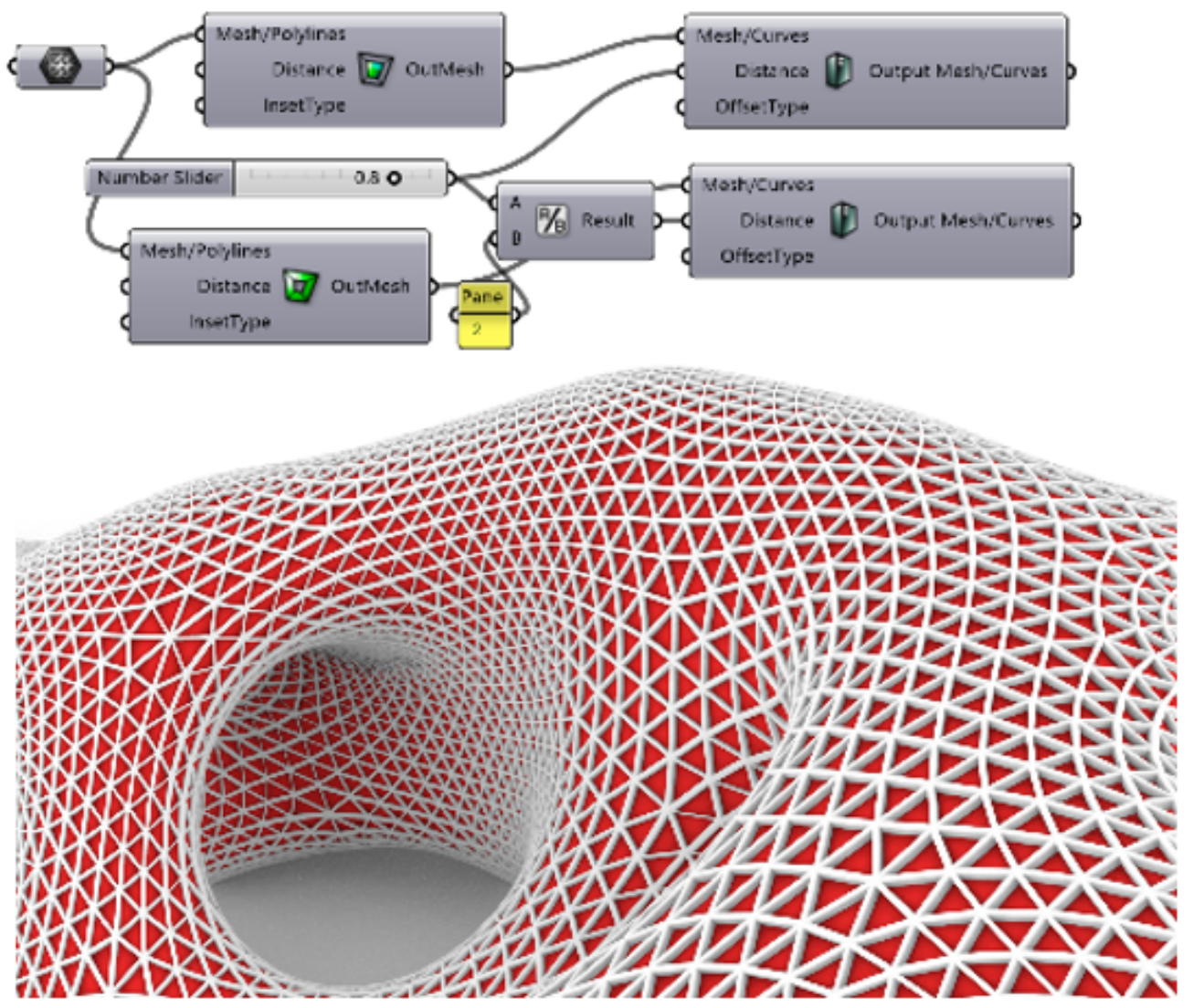

Figure 8

Skin and structure of the building. 

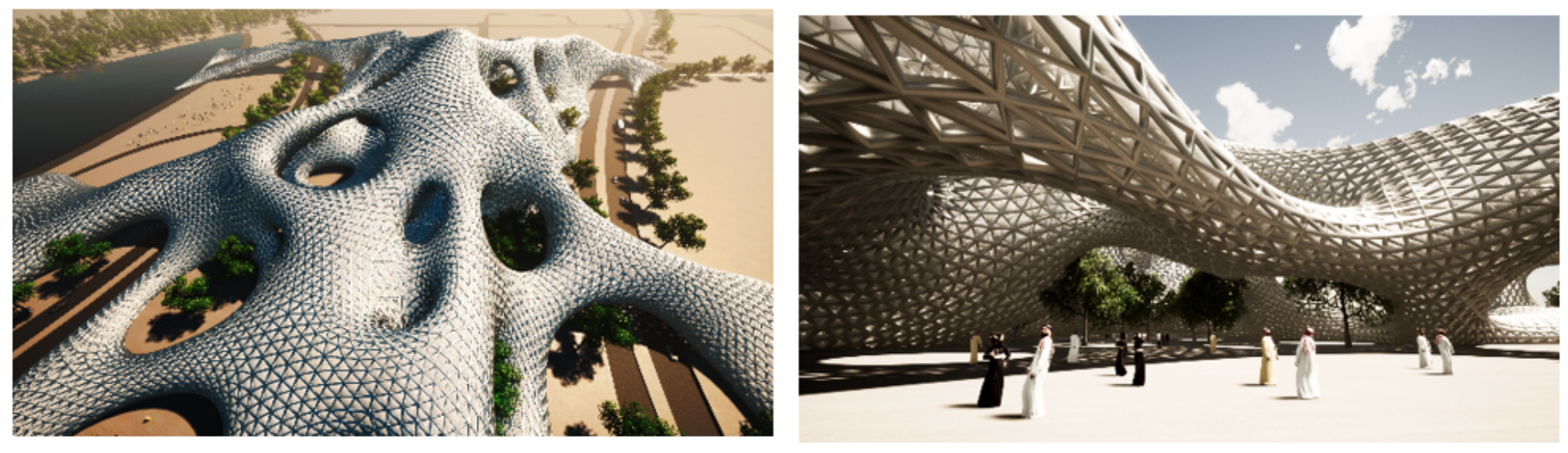

\section{Figure 9}

The final form of the building after the development stage

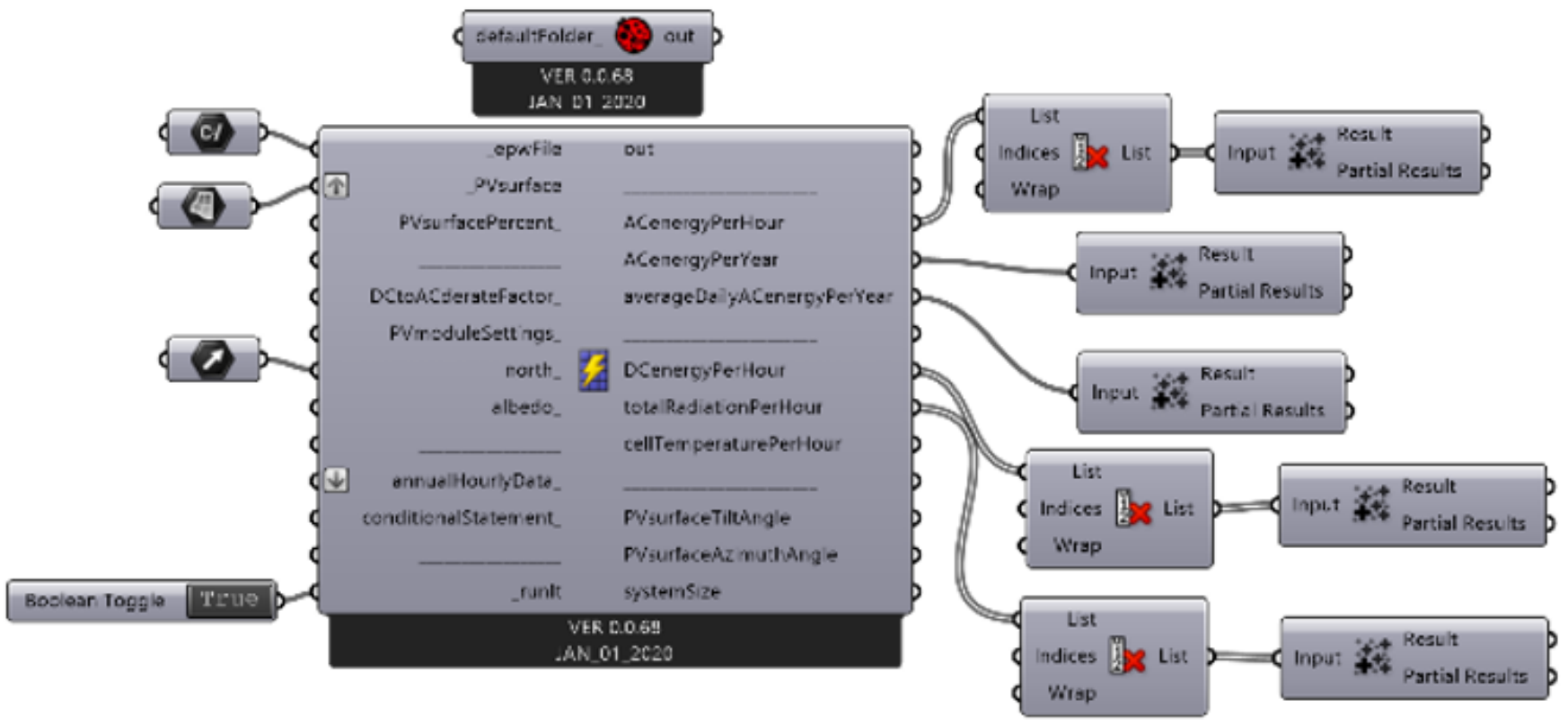

\begin{tabular}{|c|c|c|c|c|c|}
\hline & $\begin{array}{c}\text { AC Energy } \\
\text { per year } \\
(\mathrm{kWh})\end{array}$ & $\begin{array}{c}\text { Average Daily AC Energy } \\
\text { per year } \\
(\mathrm{kWh} / \text { day })\end{array}$ & $\begin{array}{c}\text { DC Energy } \\
\text { per year } \\
(\mathrm{kWh})\end{array}$ & $\begin{array}{c}\text { Total Radiation } \\
\text { per year } \\
\left(\mathrm{kWh} / \mathrm{m}^{2}\right)\end{array}$ & $\begin{array}{c}\text { Total Radiation } \\
\text { per year } \\
(\mathrm{kWh})\end{array}$ \\
\hline $\begin{array}{c}\text { Final } \\
\text { Result }\end{array}$ & 322924.56 & 884.72 & 368070.02 & 161.36 & 2689300 \\
\hline
\end{tabular}

Figure 10

Algorithm and final results of the energy use. 


\section{BEA RESULTS - Energy Use in Dubai Hotels, Malls and Schools}

\begin{tabular}{|c|c|c|c|}
\hline & Best Performers & Median & Worst Performers \\
\hline Hotels & $<171 \mathrm{kWh} / \mathrm{m}^{2}$.year & $249 \mathrm{kWh} / \mathrm{m}^{2}$.year & $>414 \mathrm{kWh} / \mathrm{m}^{2}$.year \\
\hline Resorts & $<193 \mathrm{kWh} / \mathrm{m}^{2}$.year & $334 \mathrm{kWh} / \mathrm{m}^{2}$.year & $>444 \mathrm{kWh} / \mathrm{m}^{2}$.year \\
\hline Schools & $<92 \mathrm{kWh} / \mathrm{m}^{2}$.year & $134 \mathrm{kWh} / \mathrm{m}^{2}$.year & $>233 \mathrm{kWh} / \mathrm{m}^{2}$.year \\
\hline Malls & $<378 \mathrm{kWh} / \mathrm{m}^{2}$.year & $465 \mathrm{kWh} / \mathrm{m}^{2}$.year & $>580 \mathrm{kWh} / \mathrm{m}^{2}$.year \\
\hline
\end{tabular}

Figure 11

EmiratesGBC BEA Project from the EmiratesGBC 2020 Green Building Market Brief [32].
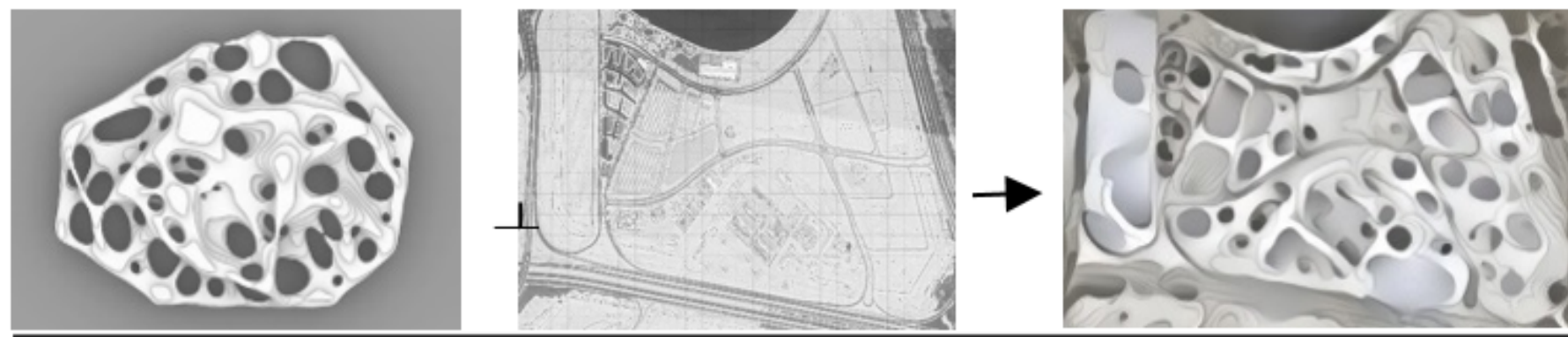

\section{Adaptive Expansion System using Al}

Al engine: depart.io

Figure 12

Using Al to predict future expansion of the building 